\section{Commentary: Stronger evidence than Arterial Revascularization Trial in patients aged 70 years or more?}

\author{
Sung Jun Park, MD, and Joon Bum Kim, MD, PhD
}

The results of the Arterial Revascularization Trial (ART) have disappointed many "artery advocates" in the field of coronary artery bypass grafting (CABG). ${ }^{1}$ Although this may not be classifiable as level A evidence, many still believe that multiple arterial revascularization may be more beneficial to patients especially for those with long life expectancy. Multiple observational studies including post hoc analyses of the ART have given strength for the pursuit of "more arterial grafting." -4 However, there are still questions surrounding bilateral internal thoracic artery (BITA) grafting when it comes to older patients with limited life expectancy.

In this issue of the Journal, Navia and colleagues ${ }^{5}$ investigated this issue using their institutional observational data. The study included 1300 patients aged 70 years or older who had undergone CABG using BITA $(n=968)$ or a single internal thoracic artery (SITA, $n=332$ ). The study is rather a comparison against "historical control" because 2 groups (BITA vs SITA) are featuring distinct operative profiles. CABGs using SITA were performed in an earlier period with on-pump strategy in a quarter of patients, whereas BITA was used in a later period almost always with offpump technique. Through a propensity-score (PS) matching analysis, the study concluded that the use of BITA provides improved 10-year survival (hazard ratio, 0.64; 95\% confidence interval, $0.44-0.94 ; P=.022$ ) compared with SITA grafting in these patients. The analysis for the current study

\footnotetext{
From the Department of Thoracic and Cardiovascular Surgery, Asan Medical Center, University of Ulsan College of Medicine, Seoul, South Korea.

Disclosures: The authors reported no conflicts of interest.

The Journal policy requires editors and reviewers to disclose conflicts of interest and to decline handling or reviewing manuscripts for which they may have a conflict of interest. The editors and reviewers of this article have no conflicts of interest.

Received for publication Oct 19, 2020; revisions received Oct 19, 2020; accepted for publication Oct 21, 2020; available ahead of print Oct 28, 2020.

Address for reprints: Joon Bum Kim, MD, PhD, Department of Thoracic and Cardiovascular Surgery, Asan Medical Center, University of Ulsan College of Medicine, 88, Olympic-Ro- 43-Gil, Songpa-Gu, Seoul, Korea 05505 (E-mail: jbkim1975@ amc.seoul.kr).

J Thorac Cardiovasc Surg 2022;164:550-1

$0022-5223 / \$ 36.00$

Copyright (c) 2020 by The American Association for Thoracic Surgery

https://doi.org/10.1016/j.jtcvs.2020.10.092
}

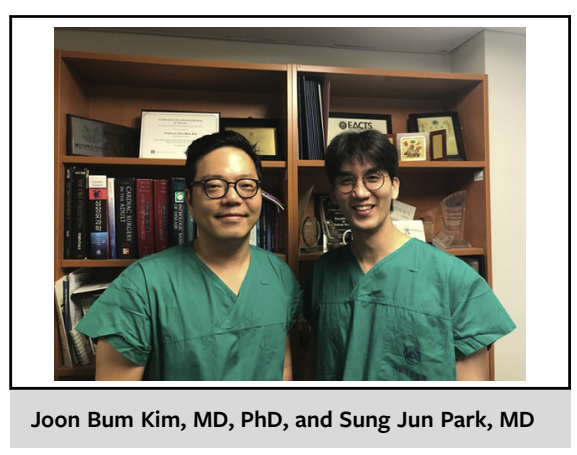

CENTRAL MESSAGE

As questions surrounding BITA grafting in elderly patients have not been properly answered yet, future clinical trials should be warranted to find an answer to

this question.

was conducted with a relatively large and homogenous sample, and the authors sought to overcome selection bias using the PS matching method. Nonetheless, the sample size was significantly reduced after PS matching, and it seems that residual confounders such as time effect have influenced the study results. Surgical outcomes always happen to improve over time as experiences accumulate, along with evolving management strategies. However, this confounder does not seem to have been adequately addressed in this comparative study between BITA and SITA. In addition, if the superior survival outcomes were to be purely due to the use of BITA in the study by Navia and colleagues, ${ }^{5}$ other outcome indexes such as myocardial infarction and repeat revascularization should have also been in favor of BITA, but were not demonstrated as such.

In this sense, it is worthwhile noting a subgroup analysis in the ART study. ${ }^{1}$ The subgroup analysis in patients aged 70 years or more in the ART study involved 406 patients with BITA and 426 patients with SITA. The 2 groups should certainly be well balanced for both measured and unmeasured variables because this is a randomized trial, and the sample size was larger than that of the study by Navia and colleagues $^{5}$ (243 matched pairs). Of note, there was no difference in terms of death from any cause between the groups (hazard ratio, 0.93 ; 95\% confidence interval, 0.75 1.16) up to 10 years in the ART. All of these considered, it is our belief that the study from Argentina entails fundamental weaknesses to gain general acceptance beyond the 
findings of the ART study. The Randomized Comparison of the Clinical Outcome of Single Versus Multiple Arterial Grafts trial is ongoing, and we look forward to finding answers from this study. ${ }^{6}$

\section{References}

1. Taggart DP, Benedetto U, Gerry S, Altman DG, Gray AM, Lees B, et al. Bilateral versus single internal-thoracic-artery grafts at 10 years. N Engl J Med. 2019;380: 437-46.

2. Gaudino M, Benedetto U, Fremes S, Biondi-Zoccai G, Sedrakyan A, Puskas JD, et al. Radial-artery or saphenous-vein grafts in coronary-artery bypass surgery. N Engl J Med. 2018;378:2069-77.
3. Taggart DP. Implications of the 10-year outcomes of the Arterial Revascularization Trial (ART) for multiple arterial grafts during coronary artery bypass graft. Eur J Cardiothorac Surg. 2019;56:427-8.

4. Taggart DP, Altman DG, Flather M, Gerry S, Gray A, Lees B, et al. Associations between adding a radial artery graft to single and bilateral internal thoracic artery grafts and outcomes: insights from the Arterial Revascularization Trial. Circulation. 2017; 136:454-63.

5. Navia D, Espinoza J, Vrancic M, Piccinini F, Camporrotonda M, Dorsa A, et al Bilateral internal thoracic artery grafting in elderly patients: any benefit in survival? J Thorac Cardiovasc Surg. 2022;164:542-9.

6. Gaudino M, Alexander JH, Bakaeen FG, Ballman K, Barili F, Calafiore AM, et al Randomized comparison of the clinical outcome of single versus multiple arterial grafts: the ROMA trial-rationale and study protocol. Eur J Cardiothorac Surg. 2017;52:1031-40.
See Article page 542.

\section{Commentary: Do you know the} way to ... 2 arterial grafts (in patients older than age 70 years)?

\author{
Frank A. Baciewicz, Jr, MD
}

The article by Navia and colleagues ${ }^{1}$ details plans to improve long-term survival to $67.0 \%$ and $66.0 \%$ with bilateral internal thoracic artery (BITA) bypass compared with survival of $56.0 \%$ and $53.0 \%$ for a single internal thoracic artery (LIMA) graft, and reverse saphenous vein grafts/ radial artery strategy in unmatched and propensity matched patients older than age 70 years undergoing coronary artery bypass grafting (CABG). Previous reviews by Lytle and colleagues $^{2}$ and Locker and colleagues ${ }^{3}$ demonstrated increased longevity in patients undergoing CABG with 2 internal thoracic or 2 arterial grafts.

In patients older than age 70 years, Mohammedi and colleagues ${ }^{4}$ suggest that BITA or all arterial graft strategies do not increase life expectancy in patients older than age

\footnotetext{
From the Department of Cardiothoracic Surgery, Michael and Marian Ilitch Department of Surgery, Wayne State University School of Medicine, Detroit, Mich.

Disclosures: The author reported no conflicts of interest.

The Journal policy requires editors and reviewers to disclose conflicts of interest and to decline handling or reviewing manuscripts for which they may have a conflict of interest. The editors and reviewers of this article have no conflicts of interest.

Received for publication Oct 27, 2020; revisions received Oct 27, 2020; accepted for publication Oct 28, 2020; available ahead of print Oct 28, 2020.

Address for reprints: Frank A. Baciewicz, Jr, MD, Department of Cardiothoracic Surgery, Michael and Marian Ilitch Department of Surgery, Wayne State University School of Medicine, Harper Hospital, 3990 John R, Detroit, MI 48201 (E-mail: fbaciewi@dmc.org).

J Thorac Cardiovasc Surg 2022;164:551-2

0022-5223/\$36.00

Copyright (c) 2020 by The American Association for Thoracic Surgery

https://doi.org/10.1016/j.jtcvs.2020.10.110
}

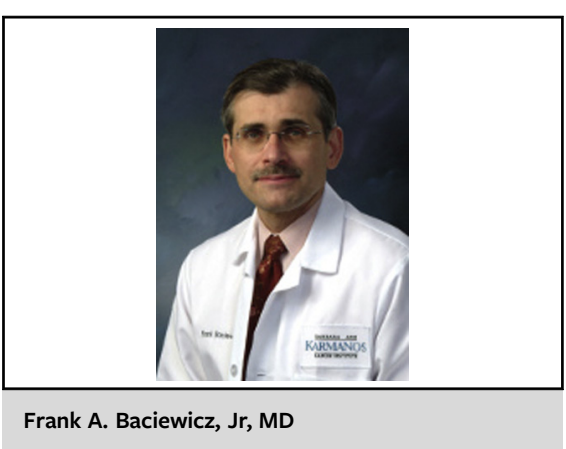

CENTRAL MESSAGE

An off-pump BITA technique demonstrated increased longterm survival in a select population older than 70 years.

60 years. In contrast, Kurlansky and colleagues ${ }^{5}$ reported increased survival in all ages with a second ITA graft.

CABG increases longevity because the LITA to left anterior descending (LAD) bypass remains patent in more than $98 \%$ of patients at 10 years. Improved long-term survival in patients with a second internal thoracic or arterial graft is related to greater arterial graft patency compared with reverse saphenous vein grafts. Studies from Shih and colleagues ${ }^{6}$ and Tinica and colleagues ${ }^{7}$ tout the high patency rate for the free right ITA (RITA) in a Y or T configuration off the LAD.

In a 2008 study, Navia and colleagues ${ }^{8}$ reported offpump BITA results with the LITA to LAD and free RITA anastomosed to the LITA (T configuration), and distally to obtuse marginal and right coronary artery 